\title{
Debates Acadêmicos por Videoconferência: uma Solução com Software Livre
}

\author{
Academic Debates by Videoconference: a Solution \\ with Free Software
}

TÂNIA BRUSQUE CROCETTA
Universidade do Estado de Santa Catarina

CARLA MARIA DE LIZ Universidade do Estado de Santa Catarina

REGIANI GUARNIERI

Faculdade de Medicina do ABC

ARGEU CARLOS THIESEN Universidade do Estado de Santa Catarina

ALEXANDRO ANDRADE Universidade do Estado de Santa Catarina

\begin{abstract}
Resumo: O objetivo deste estudo foi descrever o relato de uma experiência utilizando recursos de videoconferência com software livre para fins de defesa de mestrado em um programa de pós-graduação. A solução apresentada inclui um tablet, celular com câmera e sistema Android e os softwares freeware: Skype, DroidCam, PowerPoint OpenOffice Remote e LibreOffice Impress, além de outros recursos materiais necessários à uma sala de multimídia (projetor, computador, som, microfone entre outros). O uso do software livre para a videoconferência mostrou-se uma ótima maneira de apoiar a formação de bancas de defesa à distância permitindo a integração no processo de formação de estudantes.
\end{abstract}

Palavras-chave: Videoconferência. Inovação. Software livre. Tecnologia da informação.

\begin{abstract}
The aim of this study was to describe the report of an experiment using videoconferencing with free software for defense purposes in a Master's program. The solution presented includes a tablet, cell phone with camera and Android system, and freeware software: Skype, DroidCam, PowerPoint OpenOffice Remote e LibreOffice Impress, as well as others resources in the multimedia room (projector, computer, sound, microphone, and others). The use of free software for videoconferencing proved to be a great way to support the training of defense stalls in a distance allowing the integration of students in the training process.
\end{abstract}

Keywords: Videoconferencing. Innovation. Free software. Information technology.

CROCETTA, Tânia Brusque; et al. Debates acadêmicos por videoconferência: uma solução com software livre. Informática na Educação: teoria \& prática, Porto Alegre, v. 19, n. 3, p. 178-191, set./dez. 2016. 


\section{Introdução}

A videoconferência tem sido amplamente utilizada para a educação à distância desde que a infraestrutura de rede de computadores foi estabelecida nas sociedades (ASAI; KONDO, 2012) e a tecnologia disponível permite que as pessoas conversem, compartilhem vídeos e informações (AYAKI; SHIMADA; SATO, 2010), sendo um dos meios de comunicação que mais evoluiu durante os últimos anos (SEM; DE SARKAR, 2013, GARCIA; BELLEZI, 2014).

São diversificados os campos para utilização da videoconferência, podendo-se encontrar exemplos nas atividades educacionais (AYDIN, 2012; EL-SEMARY; AL-KHAJA, 2013), com cursos para farmacêuticos (DUALDE et al., 2009), enfermeiros (SALVADOR et al., 2010), para agentes comunitários de saúde (DAZA; BERRETIN-FELIX; MACHADO, 2014), para telepsiquiatria (CHIPPS; RAMLALL; MARS, 2012) ou para aplicação de testes neuropsicológicos (TIMPANO et al., 2013), e mais recentemente em várias ações na medicina (CAMERON; RAY; SABESAN, 2014, SEGURANYES et al., 2014), servindo ainda para aproximar crianças hospitalizadas de suas famílias, por meio de visitas virtuais, para reduzir o estresse durante a hospitalização (YANG et al., 2014).

A videoconferência realizada com o recurso da Internet (denominada webconferência) foi criada inicialmente com o objetivo de promover apenas a comunicação entre pessoas conectadas à rede mundial de computadores através da troca de dados de áudio e vídeo (GARONCE; SANTOS, 2012), utilizando softwares específicos, dentre os quais se destaca o Skype $^{T M}$ (ASAI; KONDO, 2012, GARONCE; SANTOS, 2012, SEM; DE SARKAR, 2013). Alguns estudos referem-se a videoconferência indistintamente para os recursos transmitidos pela televisão ou para os recursos veiculados pela Internet, havendo pesquisadores que optam pela diferenciação, utilizando os termos videoconferência para a primeira situação e webconferência para a segunda (PESCE; HESSEL; BRUNO, 2013). Apesar da clara diferença entre videoconferência e webconferência, para este estudo trataremos o termo videoconferência como uma comunicação interativa em áudio e vídeo para comunicação entre pessoas de diferentes localidades utilizando os recursos da Internet.

A utilização da videoconferência como ferramenta de ensino, em ambientes de educação online, tem se difundido amplamente no espaço educacional e esta possibilidade tecnológica vem motivando educadores e gestores de sistemas de ensino a empregá-la em variadas iniciativas de interação pedagógica (GARONCE; SANTOS, 2012).

A maioria das universidades exige participantes externos às bancas em praticamente todos os níveis de formação educacional, especialmente para bancas de tese de doutorado e dissertação de mestrado, onde os pesquisadores em áreas específicas estão, muitas vezes, espalhados por universidades de todo o mundo (SALIHBEGOVIC; RIBIC, 2008).

Ao mesmo tempo, a redução dos custos de aquisição de equipamentos permite que qualquer pessoa, com um computador com microfone e câmera de vídeo, possa hoje participar de uma videoconferência com grande facilidade (MARTIN-CUADRADO; LOPEZ-GONZALEZ; GARCIAARCE, 2013). 
Diante de tantas transformações presentes nas esferas privada e pública envolvidas na utilização das tecnologias da informação e comunicação (TIC), faz-se necessário buscar caminhos possíveis de apreensões, interpretações e entendimentos, enfim, maior compreensão, no sentido de se construir trajetórias progressistas face às transformações em curso (ZUIN, 2010).

Mais especificamente no sistema universitário, cabe salientar que as políticas de internacionalização da universidade encontram-se principalmente no campo de cooperação internacional de diferentes instituições governamentais de desenvolvimento de recursos humanos de ensino superior e de desenvolvimento científico e tecnológico, como a Coordenação de Aperfeiçoamento de Pessoal de Nível Superior (CAPES) e o Conselho Nacional de Desenvolvimento Científico e Tecnológico (CNPq). Tais políticas incluem formação na graduação, pós-graduação, pesquisas conjuntas, formação de recursos humanos locais e programas de formação interinstitucional (KRAWCZYK, 2008). Neste contexto, sentimo-nos na obrigação de desenvolver estratégias que potencializem parcerias e internacionalização em nossa universidade, pois este é um dos quesitos que se faz presente na avaliação dos programas de pós-graduação.

As vantagens do uso da videoconferência, com um recurso gratuito como o Skype, podem ser rapidamente identificadas (MICHELS; CHANG, 2011), mas a principal é que as bancas de defesa podem ter como convidados externos, membros de diversos estados e/ou países, o que talvez fosse impossibilitado pelo alto custo de passagens aéreas e hospedagens (WYNN; HAGEN; FRIBORG, 2012), além da reduzida agenda dos pesquisadores participantes, sem contar com situações em que mesmo o candidato à defesa não pode estar fisicamente presente, como nos casos de doença ou gravidez, ou até a indisponibilidade dos vistos necessários para um dos membros da banca (SALIHBEGOVIC; RIBIC, 2008).

A publicação deste artigo tem como objetivo descrever um relato de experiência sobre a utilização da videoconferência em uma defesa de mestrado no Programa de Pós-graduação em Ciências do Movimento Humano do Centro de Ciências da Saúde e do Esporte da Universidade do Estado de Santa Catarina, visando incentivar a utilização deste recurso inovador nos programas de pós-graduação no Brasil.

\subsection{Breve Histórico da Utilização da Videoconferência no Centro de Ciências da Saúde e do Esporte (CEFID)}

O Programa de Pós-Graduação do Centro de Ciências da Saúde e do Esporte (CEFID) da Universidade do Estado de Santa Catarina (UDESC) através da Resolução 034/2012 do Conselho de Ensino, Pesquisa e Extensão (CONSEPE, 2012), alterou o Regimento do seu Programa para que as qualificações e defesas de Mestrado e Doutorado sejam realizadas em sessão pública ou por videoconferência, incentivando a utilização deste recurso. Tal resolução se deu especialmente pela exigência da CAPES/CNPq, de que em bancas de defesas e qualificações exista a participação de membros externos, ou seja, de outras instituições de ensino.

No ano de 2012, o CEFID teve sua primeira experiência com a utilização da videoconferência na defesa de doutorado da tese intitulada "Perfil de Humor de atletas vencedores de 
modalidades individuais e coletivas". A experiência, até então nunca vivenciada no Programa de Pós-graduação em Ciências do Movimento Humano se deu por meio da participação em banca de um convidado externo que não poderia comparecer na defesa caso essa fosse de modo presencial, devido à indisponibilidade de agenda. Tal professor é vinculado a Universidade de Vigo - UNIVIGO na Espanha.

Em 2013, em função da experiência vivenciada em 2012, outras duas defesas, uma de doutorado e outra de mestrado, contaram com a participação de membros externos por meio de videoconferência. Vale destacar que no caso da defesa de mestrado ocorrida, o participante externo que residia em São Paulo encontrava-se no momento da defesa, na cidade de Boston/EUA. Este professor é vinculado a Faculdade de Medicina do ABC - SP.

No ano de 2014, a videoconferência foi utilizada em duas qualificações de mestrado para possibilitar a participação de convidados externos para sua avaliação. Na primeira, o professor que reside em Porto Alegre/RS, está vinculado a Universidade Federal do Rio Grande do Sul UFRGS. Na segunda qualificação de mestrado citada se obteve a participação de um professor vinculado a Universidade da Carolina do Norte, o qual estaria impossibilitado de comparecer à qualificação caso esta exigisse o modo presencial. Vale destacar que este professor, devido à facilidade de trocas de experiências, disponibilizada por videoconferência, mantêm contato com os pesquisadores do CEFID auxiliando no projeto de extensão intitulado "Efeito do Exercício Físico nos aspectos psicológicos de portadores e sobreviventes de câncer".

A partir da experiência vivenciada, e cientes das vantagens acerca do uso da videoconferência para procedimentos de defesas de mestrado e doutorado bem como para firmar parcerias com instituições nacionais e/ou internacionais, outros grupos de pesquisa do CEFID começaram a utilizar o recurso da videoconferência. Atualmente, o CEFID vem ampliando o número de defesas de mestrado e doutorado registradas, que se utilizaram deste recurso para viabilizar a participação de membros externos nacionais e/ou internacionais em suas bancas.

\section{Material e Métodos}

Para viabilizar a videoconferência com o convidado externo no momento da defesa de mestrado, foram necessários softwares freeware, equipamentos e materiais de apoio, tais descritos a seguir:

\subsection{Skype $^{T M}$}

O Skype TM (http://www.skype.com/pt-br/) é um aplicativo que permite que os usuários se comuniquem uns com os outros em tempo real, usando protocolo internet (VoIP = Voz sobre IP), vídeo chat, ou chat de texto (ZHANG et al., 2012) e que ganhou grande popularidade por facilmente trabalhar em diferentes ambientes de rede, uma vez que pode detectar automaticamente as características da rede e usar outros computadores para retransmitir o seu tráfego (FREIRE et al., 2008). O Skype ${ }^{T M}$ requer apenas o registro de uma conta que serve para efetivar a chamada, depois de aceite do convite do interlocutor. O software está disponível para download no site do fabricante Skype ${ }^{T M}$ (SKYPE, 2014). A página principal já oferece a opção "Baixar o Skype", que direciona à uma página para baixar a versão para Windows ${ }^{\circledR}$ ou Mac $^{\circledR}$, 
dependendo da versão do sistema operacional desejado. Para a apresentação da imagem da apresentadora, a configuração foi alterada em "Ferramentas - Opções - Configuração de vídeo" para utilizar a imagem capturada pelo celular com câmera.

\subsection{DroidCam Wireless Webcam}

DroidCam

Wireless

Webcam

(https://play.google.com/store/apps/details?id=com.dev47apps.droidcam\&hl=pt_BR) é um aplicativo que transforma um dispositivo portátil, como um celular ou tablet que use um sistema operacional Android em uma webcam sem fio, possibilitando conversas com transmissão de imagens no Skype ${ }^{T M}$, Google+ e outros programas (DEV47APPS, 2014) em tempo real. No computador portátil da sala, denominado de PC-SalaSom foi instalado um componente de PC cliente que instala os drivers de webcam que se conecta com o dispositivo Android portátil através do endereço de internet (InternetProtocol - IP). Portanto, a imagem transmitida pelo Skype estava sendo capturada por um dispositivo portátil, usando este aplicativo e não pela câmera do notebook (PC-SalaSom), bastando alterar a configuração de vídeo na opção "Ferramentas-Opções" do Skype. O software está disponível para download no site do fabricante DEV47APPS (DEV47APPS, 2014) ou através de uma conta no GooglePlay ${ }^{\odot}$, sendo um aplicativo para ser executado no tablet e outro (cliente) para ser executado no computador. No site do desenvolvedor também estão todas as instruções para configuração e sincronização entre o computador que transmitiria a imagem e o som da apresentação (PC-SalaSom) e a câmera do telefone portátil, sendo necessário informar o endereço IP do telefone portátil.

\subsection{PowerPoint OpenOffice Remote}

Com o aplicativo PowerPoint OpenOffice Remote (http://www.androidpowerpoint.com/powerpoint/) é possível comandar, a partir do tablet, a apresentação dos slides que está em execução no software de apresentação de slides (LibreOfficeImpress, MS Power Point, entre outros) ao computador que conectado ao projetor transmitia a apresentação para o auditório, denominado de (PC-Auditório) de forma remota (REMOTE, 2014). Permite ainda que as anotações de cada slide fiquem visíveis apenas ao apresentador (no tablet). Na tela do PCAuditório os slides eram mostrados de forma integral para os participantes e projetadas no telão pelo projetor multimídia. O software está disponível para download no site do desenvolvedor Ralf Wondratschek (WONDRATSCHEK, 2014) ou através de uma conta no GooglePlay ${ }^{\odot}$, sendo um aplicativo para ser executado no tablet e outro (cliente) para ser executado no computador. No site do desenvolvedor também estão todas as instruções para configuração e sincronização entre o PC-Auditório e tablet, sendo necessário informar o endereço IP do computador (PCAuditório).

\subsection{LibreOfficeImpress}

O LibreOfficeImpress (http://pt-br.libreoffice.org/descubra/impress/) é uma ferramenta desenvolvida para a criação de apresentações multimídia e que possui uma variedade de recursos que facilitam a utilização da ferramenta de desenho e diagramação, que adicionam 
estilo e sofisticação à uma apresentação (LIBREOFFICE, 2014). O LibreOffice é um projeto brasileiro com ferramentas de escritório, distribuído de forma livre e aberta. Com o Impress é possível salvar a apresentação em formato ODF, o novo padrão internacional para a criação de documentos, como também abrir e salvar arquivos do Microsoft PowerPoint. O software está disponível para download no site do desenvolvedor LibreOffice Foundation.

\subsection{Conexão de área de trabalho remota}

Este recurso acompanha as versões do Windows, permitindo a conexão de dois computadores através de uma rede ou da Internet, sendo possível acessar todos os programas e arquivos existentes no computador remoto, bastando apenas informar o IP do computador onde se deseja realizar a conexão.

\subsection{Tablet}

Samsung Galaxy Note 10.1, GT-N8000, com sistema Android versão 4.1.2. O equipamento foi configurado para conectar-se ao roteador wireless, ativando o Wi-Fi do mesmo. Uma larga faixa elástica preta envolvia a capa do tablet permitindo que ficasse preso à mão da apresentadora, dando-Ihe flexibilidade de movimentos. A passagem dos slides da apresentação era comandada pelo softwarePowerPoint OpenOffice Remote instalado no tablet (Figura 1 número 9). A configuração requer apenas que se obtenha o IP do computador onde se encontra a apresentação.

\subsection{Celular com câmera}

Modelo Samsung GalaxyPocket GT-S5301B, com sistema Android versão 4.0.4, com uma câmera traseira. $O$ equipamento foi configurado para conectar-se ao roteador wireless, ativando o Wi-Fi do mesmo. O chip da operadora foi retirado para garantir que não receberia nenhuma chamada. Nele foi instalado o aplicativo DroidCam que permite o envio remoto das imagens capturadas para o PC-SalaSom (Figura 1 - número 7).

\subsection{PC-Auditório}

Desktop Dual Core com Windows 7. Na saída VGA estava ligado o cabo de vídeo ao projetor multimídia, de onde eram projetados os slides do LibreOfficeImpress e a passagem dos slides comandadas remotamente pelo tablet na mão da apresentadora (Figura 1 - número 2). Neste computador foi instalado o aplicativo cliente do PowerPoint OpenOffice Remote necessário para a sincronização e passagem dos slides.

\subsection{PC-SalaSom}

Notebook Dual Core com Windows XP, ligado a uma mesa de som de 8 canais que gerencia o som do auditório. A entrada de áudio do PC-SalaSom (microfone) foi ligada em um canal de saída (output) da mesa de som. Isso permitiu o envio do som ao participante externo - som dos 
microfones do auditório. A saída de áudio do PC-SalaSom (caixas de som) foi ligada em um canal de entrada (input) da mesa de som. Isso permitiu que a voz do participante externo fosse amplificada nos alto-falantes do auditório. Neste computador estavam instalados o Skype e o componente de captura das imagens do DroidCam (Figura 1 - número 4). Desta forma era possível a transmissão das imagens capturadas pelo celular para o participante externo, bem como a transmissão do som capturado pela mesa de som.

\subsection{Roteador wireless}

Roteador Linksys WRT54GL com tecnologia Wireless-G, na faixa de frequência de $2,4 \mathrm{GHz}$, padrões IEEE 802.3, IEEE 802.3u, IEEE 802.11g, IEEE 802.11b, com duas antenas externas. $\mathrm{O}$ roteador foi configurado com senha para que fosse utilizado apenas pelos equipamentos da videoconferência (tablet, celular e os dois PCs) (Figura 1 - número 6), impedindo que outros equipamentos pudessem se conectar e comprometer a velocidade da conexão.

\subsection{Projetor multimídia}

Projetor Epson PowerLite $X 12$ preso ao teto do auditório e projetando a imagem na parede branca (Figura 1 - números 1 e 3), ligado ao PC-Auditório. Durante a apresentação da defesa eram projetados os slides e quando da fala do membro externo, era transmitida a imagem captura pelo Skype ${ }^{T M}$ instalado no PC-SalaSom.

\subsection{Mesa de som}

Mesa de som com oito canais existente no auditório (Figura 1 - número 5). Um canal de entrada utilizado para o microfone sem fio de lapela, um canal de entrada para o microfone sem fio, um canal de saída para as caixas de som do auditório, um canal de entrada para a conexão do fone de ouvido do PC-SalaSom (para receber a voz do participante externo) e um canal de saída para a conexão do microfone do PC-SalaSom (para enviar o som dos microfones do auditório para o participante externo).

\subsection{Caixas acústicas}

Autofalantes embutidos no teto do auditório (Figura 1 - número 8 ) que distribuíam o som para todos os participantes, tanto dos microfones utilizados pela apresentadora quanto pela banca e membro externo.

\subsection{Microfone sem fio de lapela}

Microfone sem fio de lapela da marca Karsect, ligado à mesa de som (input), utilizado pela apresentadora (Figura 1 - número 14) com receptor preso a cintura.

\subsection{Microfone sem fio}

Microfone sem fio da marca Shure, ligado à mesa de som, utilizado pelos doutores membros da banca presentes no auditório (Figura 1 - número 13). 


\subsection{Apontador}

Apontador com feixe de luz a laser (Figura 1 - número 10).

No que tange aos procedimentos adotados para a realização da videoconferência no momento da defesa de mestrado, estes seguiram da seguinte maneira:

Os equipamentos (tablet, celular, dois PCs e roteador wireless) foram conectados em rede, todos com acesso à Internet. O chip do celular foi retirado para que não houvesse nenhuma chamada. O celular ficou preso a um pedestal a uma altura adequada, de forma que a câmera capturasse a maior parte da área de circulação da apresentadora e parte dos membros da banca. A voz da apresentadora era capturada por um microfone sem fio de lapela, cujo receptor ficava ligado a uma mesa de som do auditório. Portanto a voz era claramente ouvida pelos participantes no auditório e pelo membro da banca, o pesquisador que estava em Boston - EUA.

No PC-Auditório estava conectado o cabo de vídeo do projetor multimídia. No PC-SalaSom estavam conectados dois cabos de áudio P2-P10 à mesa de som localizada em uma sala de som nos fundos do auditório: um cabo na entrada do microfone e outro na saída de som. Também no PC-SalaSom estava conectado o Skype ${ }^{T M}$ com o membro da banca em Boston e configurado para transmitir as imagens capturadas pelo celular.

A apresentadora prendeu o tablet à mão esquerda com uma faixa elástica, deixando a mão direita livre para gerenciar a passagem dos slides da apresentação. $O$ aplicativo PowerPoint OpenOffice Remote permitia que a apresentadora visualizasse as anotações de cada slide. Também com a mão direita a apresentadora utilizava o apontador sempre que necessário (Figura 1).

Figura 1 - Desenho esquemático com o posicionamento de todos os equipamentos e materiais de apoio utilizados neste relato do debate ocorrido por videoconferência com utilização de software livre. 


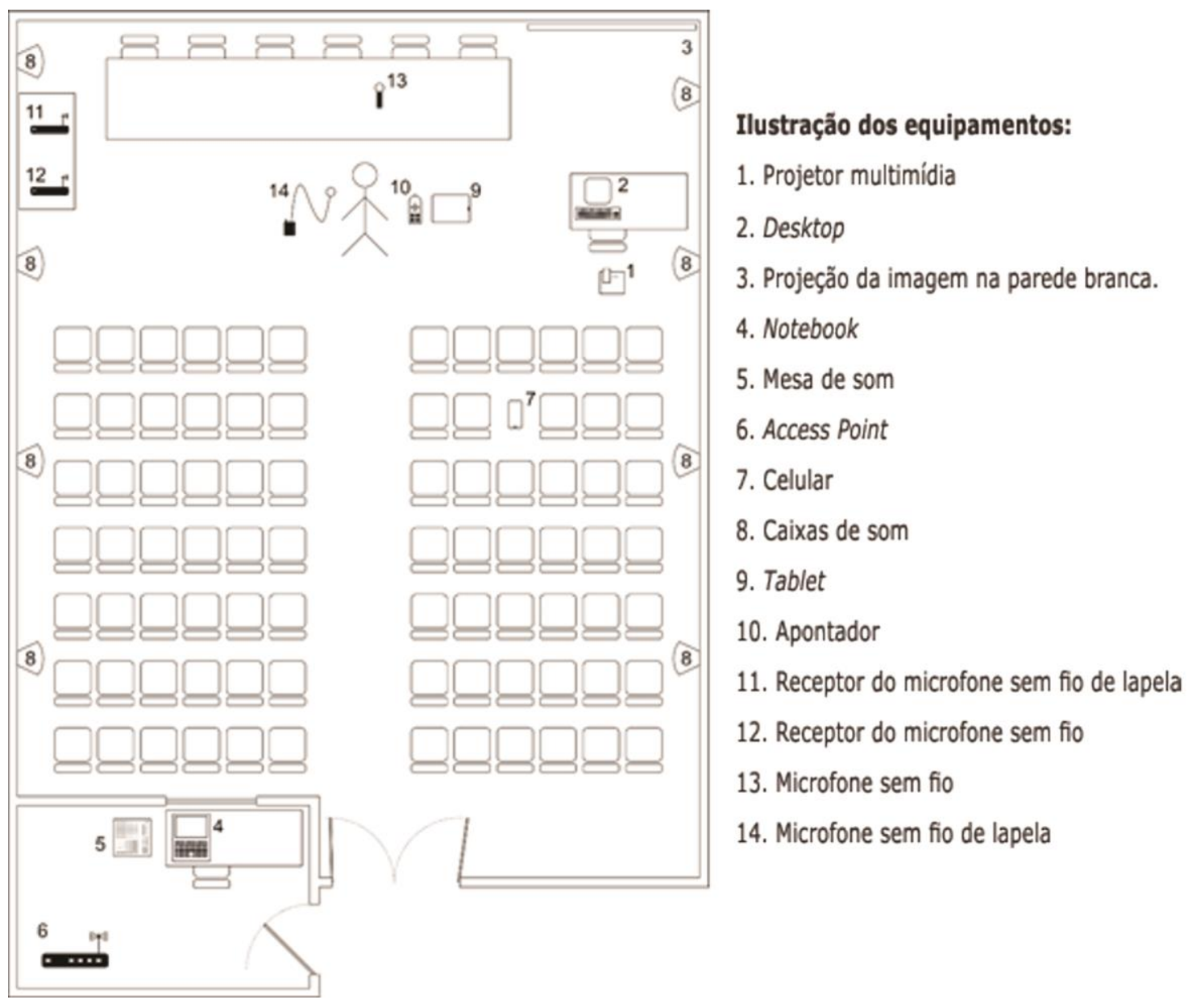

Fonte: elaborada pelos autores.

Ao final da apresentação, a mesa de defesa foi composta pelos cinco doutores (presenciais) e o presidente abriu os trabalhos dando a palavra ao membro externo conectado ao Skype ${ }^{T M}$. Neste momento, foi necessário acionar a opção de Conexão de Área de Trabalho Remota do PCAuditório com o PC-SalaSom. Assim, a imagem do professor em Boston foi projetada no telão do auditório, bem como sua voz para todos os presentes no auditório.

A defesa levou cerca de quatro horas, e durante todo este tempo não houve nenhuma perda de sinal ou quebra da qualidade de som ou imagem. A fala do membro da banca em Boston, de cerca de 30 minutos, foi acompanhada claramente por todos os presentes no auditório, não havendo nenhum atraso ou cortes no áudio.

A repercussão positiva do uso destes recursos tem motivado os alunos a estenderem o convite para participação de membros de outros estados e países em bancas de mestrado e doutorado. Verifica-se que a videoconferência está se expandindo a cada ano como um método de divulgação de resultados de pesquisas e de boas práticas sendo uma ferramenta para compartilhamento de informação e divulgação (SUDUC et al., 2010).

Algumas recomendações se fazem necessárias para que a solução proposta neste relato obtenha o sucesso desejado: 
- Realize um teste com o participante externo pelo menos um dia antes da apresentação, e verifique se a iluminação, o som, a disposição dos demais membros da banca, os espectadores e outros parâmetros devem ser ajustados;

- O som e iluminação devem estar adequados para o membro externo, mas também para os membros locais;

- Identifique o espaço de movimentação que pode ser executado durante a apresentação para que sua imagem seja adequadamente transmitida;

- Mesmo com o teste realizado anteriormente, faça um teste rápido com o participante externo alguns minutos antes da apresentação se iniciar;

- Envie uma cópia da sua apresentação para o participante externo, pois se não for possível a visualização adequada dos slides pela imagem transmitida, ele poderá acompanhar sua apresentação;

- Oriente o membro externo para manter o microfone como "mudo" enquanto ele não estiver falando para evitar ruídos de fundo;

- Avalie a possibilidade de que o serviço internet possa não estar disponível em um dos lados da videoconferência e combine estratégias para este fato, como o uso de um telefone para transmitir a voz do apresentador ou do membro externo.

O desafio desta experiência foi utilizar uma grande quantidade de recursos tecnológicos, porém, uma configuração com menos recursos poderá alcançar o mesmo objetivo, além de existirem outras configurações de software e hardware.

Uma das preocupações que se deve ter em mente ao se utilizar os recursos da videoconferência, diz respeito a largura de banda, pois muitas vezes, a transmissão de vídeo e voz consomem grande volume de dados, sendo necessários ajustes que normalmente referemse a redução da qualidade da imagem e favorecendo a qualidade da voz (SABESAN; VAN HOUTS; PARKINSON, 2010, GARCIA; BELLEZI, 2014). Para esta experiência, foram realizados testes no dia anterior à realização da defesa além de terem sido reduzidas as qualidades da imagem transmitidas pelo celular. Importante configurar o roteador Wireless com senha apenas para o evento, impedindo que o recurso pudesse ser requerido por outro dispositivo que estivesse próximo ao auditório.

Existem limitações quanto a utilização da videoconferência, principalmente no que tange a necessidade de conhecimentos técnicos adequados para o uso dos recursos compartilhados em rede, principalmente da configuração de cada software, no entanto, esta foi uma nova maneira de usar a tecnologia disponível, e ao mesmo tempo, uma oportunidade de compartilhar e escrever sobre a experiência vivenciada.

O Skype ${ }^{T M}$ pode não ser a melhor escolha para videoconferência porque os slides do PowerPoint ou LibreOfficeImpress devem ser alterados manualmente em ambos os lados (SALIHBEGOVIC; RIBIC, 2008), mas esta desvantagem pode ser compensada pela facilidade de utilização do Skype ${ }^{T M}$.

São diversas soluções de videoconferência, porém existe a necessidade de se escolher a aplicação que seja ideal, dentro dos limites de recurso e conhecimento técnico. A configuração 
apresentada neste trabalho requer conhecimentos básicos, pois todos os softwares são de rápida configuração, sendo o mais robusto o de apresentação de slides (LibreOfficeImpress), mas este já é de largo conhecimento, existindo outros no mercado, como o MS Power Point, porém este requer aquisição de licença de uso. Além disso, outros recursos podem ser substituídos, principalmente no que se refere ao equipamento de som, que pode ser substituído por simples caixas de som ligadas ao computador em um único ambiente. Neste trabalho fizemos uso dos recursos que já estavam disponíveis no auditório.

\section{Considerações finais}

Com o objetivo de apresentar um relato de experiência acerca da utilização da videoconferência em uma banca de mestrado com membros simultâneos em diferentes locais, este trabalho valoriza as ferramentas de Tecnologia da Informação e Comunicação (TIC) disponíveis e presentes em nosso cotidiano, além de indicar a possibilidade de inovar na utilização de recursos de software livre.

Apesar da necessidade do envolvimento de algum conhecimento técnico para montagem da proposta aqui apresentada, todos os recursos possuem bons tutoriais disponíveis na Internet para orientação da configuração necessária e a preparação antecipada deve sempre considerada.

A crescente utilização da videoconferência nas qualificações e defesas de dissertações e teses, nos apoia em recomendar a utilização deste recurso nos processos de formação e debate acadêmico, ampliando a divulgação dos estudos e pesquisas realizadas, contribuindo para as discussões dos pesquisadores e reduzindo a limitação das distâncias geográficas e dos desgastes nos deslocamentos.

\section{Agradecimentos}

Programa UNIEDU-SC de pós-graduação. 


\section{Referências}

ASAI, K.; KONDO, K. Supporting presentation with mobile PC in distance lecture. Information Technology Based Higher Education and Training (ITHET), 2012 International Conference on, 2012, 21-23 June 2012. p.1-6.Acesso em: 29.mai.2014

AYAKI, R.; SHIMADA, H.; SATO, K. Online Personal Connection Presentation System for Communication Assistance. Embedded and Ubiquitous Computing (EUC), 2010 IEEE/IFIP 8th International Conference on, 2010, 11-13 Dec. 2010. p.380-385.Acesso em: 29.mai.2014

AYDIN, I. E. Relationship between affective learning, instructor attractiveness and instructor evaluation in videoconference-based distance education courses. Turkish Online Journal of Educational Technology, v. 11 n. 4, p. 247-252, Oct 2012. ISSN 2146-7242. Acesso em: 12.set.2014

CAMERON, M. P. L.; RAY, R.; SABESAN, S. Physicians' perceptions of clinical supervision and educational support via videoconference: a systematic review. Journal of Telemedicine and Telecare, v. 20, n. 5, p. 272 281, Jul 2014. ISSN 1357-633X; 1758-1109. Disponível em: <<Go to ISI >://WOS:000338843500008 >. Acesso em: 12.set.2014

CHIPPS, J.; RAMLALL, S.; MARS, M. Practice guidelines for videoconference-based telepsychiatry in South Africa. African Journal of Psychiatry, v. 15, n. 4, p. 271-282, Jul 2012. ISSN 1994-8220. Disponível em: $<<$ Go to ISI >://WOS:000306941800009 >. Acesso em: 12.set.2014

CONSEPE. RESOLUÇÃo No 034/2012 - CONSEPE. Resoluções do Conselho de Ensino, Pesquisa e Extensão CONSEPE, Florianópolis - SC, 2012. Disponível em: < http://www.udesc.br/?id=744\#resol2012 >. Acesso em: 30.mai.2014.

DAZA, M. P. M.; BERRETIN-FELIX, G.; MACHADO, M. A. M. D. P. Requisitos para utilização de cybertutor com agentes comunitarios de saúde. Revista CEFAC, v. 16, n. 2, p. 573-581, 2014-04 2014. ISSN 19820216. Disponível em: <<Go to ISI>://SCIELO:S1516-18462014000200573 >. Acesso em: 12. set.2014

DEV47APPS. DroidCam Wireless Webcam. 2014. Disponível em: < https://play.google.com/store/apps/details?id=com.dev47apps.droidcam\&hl=pt_BR >. Acesso em: 30.mai.2014.

DUALDE, E. et al. Effectiveness of a videoconference training course on implementing pharmacy services. Pharmacy World \& Science, v. 31, n. 6, p. 638-642, Dec 2009. ISSN 0928-1231. Disponível em: <<Go to ISI > ://WOS:000271087700009 >. Acesso em: 12.set.2014

EL-SEMARY, H.; AL-KHAJA, M. Assessing the Effectiveness of Videoconferencing in Education; Case Study of UAE University. 2013 International Conference on Creative Education (Icce 2013), Vol 1, v. 3, p. 116-123, 2013 2013. ISSN 2339-5141. Disponível em: <<Go to ISI >://WOS:000340492200021 >. Acesso em: 12.set. 2014

FREIRE, E. P. et al. Detecting Skype flows in web traffic. 2008 Ieee Network Operations and Management Symposium, Vols 1 and 2, p. 89-96, 2008 2008. ISSN 1542-1201. Disponível em: <<Go to ISI >://WOS:000259262400012 >. Acesso em: 03.jun.2014

GARCIA, D. C.; BELLEZI, M. A. Análise de Aplicativos para Videoconferência em Sistemas Móveis na Plataforma Android. Revista TIS, v. 3, n. 1, 2014. ISSN 2316-2872. Acesso em: 30.mai.2014

GARONCE, F.; SANTOS, G. L. Transposição midiática: da sala de aula convencional para a presencial conectada. Educação \& Sociedade, v. 33, n. 121, p. 1003-1017, 2012-12 2012. ISSN 0101-7330. Disponível em: <<Go to ISI >://SCIELO:S0101-73302012000400005 >. Acesso em: 29.mai.2014

KRAWCZYK, N. R. As políticas de internacionalização das universidades no Brasil: o caso da regionalização no Mercosul. Jornal de Políticas Educacionais, v. 2, n. 4, 2008. ISSN 1981-1969. Acesso em: 10.jul.2014

LIBREOFFICE. Impress - Crie apresentações convincentes. 2014. Disponível em: < http://ptbr.libreoffice.org/libreoffice/impress/ >. Acesso em: 30.mai.2014. 
MARTIN-CUADRADO, A. M.; LOPEZ-GONZALEZ, M. A.; GARCIA-ARCE, A. Innovation Network: Videoconferencing as a Resource in Teaching Support and Autonomous Learning. Tecnologias del Aprendizaje, IEEE Revista Iberoamericana de, v. 8, n. 3, p. 119-125, 2013. ISSN 1932-8540. Acesso em: 13.set. 2014

MICHELS, B. J.; CHANG, C.-W. Attending a Presentation at a Distance in Real-time via Skype. TechTrends, v. 55, n. 1, p. 23-27, 2011/01/01 2011. ISSN 8756-3894. Disponível em: < http://dx.doi.org/10.1007/s11528-011-0465-0 >. Acesso em: 29.mai.2014

PESCE, L.; HESSEL, A.; BRUNO, A. R. Experiências com webconferência: a constituição de comunidades de aprendizagem 2013

REMOTE, P. O. PowerPoint Remote. 2014. Disponível em: < http://www.androidpowerpoint.com/powerpoint/ >. Acesso em: 16.jun.2014.

SABESAN, S.; VAN HOUTS, B.; PARKINSON, C. Factors to consider when starting up a videoconference medical oncology outreach clinic. Australian Journal of Rural Health, v. 18, n. 2, p. 89-90, Apr 2010. ISSN 1038-5282. Disponível em: <<Go to ISI >://WOS:000276016200010 >. Acesso em: 13.set.2014

SALIHBEGOVIC, A.; RIBIC, S. Defending a PhD thesis over the internet: Challenges and obstacles. Proceedings of the Iti 2008 30th International Conference on Information Technology Interfaces, p. 563568, 2008 2008. ISSN 1330-1012. Disponível em: <<Go to ISI>://WOS:000259054100088 >. Acesso em: 13.set. 2014

SALVADOR, M. E. et al. Using videoconferencing to discuss themes of nursing management in university hospitals. Acta Paulista De Enfermagem, v. 23, n. 5, p. 705-707, Sep-Oct 2010. ISSN 0103-2100. Disponível em: <<Go to ISI>://WOS:000285739400020 >. Acesso em: 23.set.2014

SEGURANYES, G. et al. Efficacy of a videoconferencing intervention compared with standard postnatal care at primary care health centres in Catalonia. Midwifery, v. 30, n. 6, p. 764-771, Jun 2014. ISSN 0266-6138; 1532-3099. Disponível em: <<Go to ISI >://WOS:000336496600025 >. Acesso em: 23.set.2014

SEN, S.; DE SARKAR, A. Design of Video Conferencing Solution in Grid. Advances in Computing and Information Technology, Vol 2, v. 177, p. 445-457, 2013 2013. ISSN 2194-5357. Disponível em: <<Go to ISI > ://WOS:000312968800046 >. Acesso em: 23.mai.2014

SKYPE. Encontrem-se em uma chamada de vídeo em grupo gratuita. 2014. Disponível em: < www.skype.com/pt_BR/ >. Acesso em: 30.mai.2014.

SUDUC, A. M. et al. Using web conferencing for disseminating the educational projects results. Innovation and Creativity in Education, v. 2, n. 2, p. 2813-2818, 2010 2010. ISSN 1877-0428. Disponível em: <<Go to ISI >://WOS:000282002802135 >. Acesso em: 29.ago.2014

TIMPANO, F. et al. Videoconference-Based Mini Mental State Examination: A Validation Study. Telemedicine and E-Health, v. 19, n. 12, p. 931-937, Dec 1 2013. ISSN 1530-5627; 1556-3669. Disponível em: <<Go to ISI > ://WOS:000327786200007 >. Acesso em: 23.set.2014

WONDRATSCHEK, R. Ralf Wondratschek. 2014. Disponível em: < http://www.android-powerpoint.com/ralf >. Acesso em: 30.mai.2014.

WYNN, R.; HAGEN, K.; FRIBORG, O. Videoconferencing at a centre for rare disorders: user satisfaction and user participation. Acta Paediatrica, v. 101, n. 2, p. E83-E85, Feb 2012. ISSN 0803-5253. Disponível em: $<<$ Go to ISI $>$ ://WOS:000298914000008 >. Acesso em: 12. set.2014

YANG, N. H. et al. Videoconferencing to Reduce Stress Among Hospitalized Children. Pediatrics, v. 134, n. 1, p. E169-E175, Jul 2014. ISSN 0031-4005; 1098-4275. Disponível em: $<<$ Go to ISI > ://WOS:000338774800022 >. Acesso em: 12.set.2014

ZHANG, X. et al. Profiling Skype Video Calls: Rate Control and Video Quality. 2012 Proceedings Ieee Infocom, p. 621-629, 2012 2012. Disponível em: <<Go to ISI >://WOS:000309279500070 >. Acesso em: 03.jun. 2014 
ZUIN, A. A. S. O Plano nacional de educação e as tecnologias da informação e comunicação. Educação \& Sociedade, v. 31, p. 961-980, 2010. ISSN 0101-7330. Disponível em: < http://www.scielo.br/scielo.php?script=sci_arttext\&pid=S0101-73302010000300016\&nrm=iso >. Acesso em: 25.ago.2014

Submetido para avaliação em 06 de dezembro de 2015.

Aprovado para publicação em 08 de março de 2016.

\section{Tânia Brusque Crocetta}

Universidade do Estado de Santa Catarina - UDESC, Florianópolis, SC, Brasil, tania.crocetta@udesc.br

Carla Maria de Liz

Universidade do Estado de Santa Catarina - UDESC, Florianópolis, SC, Brasil, carla.maria.liz@gmail.com

\section{Regiani Guarnieri}

Faculdade de Medicina do ABC - FMABC, Santo André, SP, Brasil, regianig1@gmail.com

\section{Argeu Carlos Thiesen}

Universidade do Estado de Santa Catarina - UDESC, Florianópolis, SC, Brasil, argeu.thiesen@udesc.br

\section{Alexandro Andrade}

Universidade do Estado de Santa Catarina - UDESC, Florianópolis, SC, Brasil, alexandro.andrade@udesc.br 